\title{
Contribuições do terceiro setor para o desenvolvimento de uma escola em sintonia com realidade local - a experiência da Fundação Tide Setubal
}

Thais Christofe Garrafa * Beatriz Penteado Lomonaco**

\section{RESUMO}

* Psicóloga e Psicanalista. Desenvolve atividades Com o objetivo de contribuir com o fortalecimento da educação clínicas e formativas formal em territórios urbanos de alta vulnerabilidade social, o relacionadas à psicanálise e atua no terceiro setor há dez anos. Atualmente, trabalha para o Núcleo de Gestão do Conhecimento da Fundação Tide Setubal.

** Psicóloga, doutora em Sciences de l'Education pela Universidade Paris VIII, pós-doutora pela FEUSP, trabalha no terceiro presente artigo põe em discussão as intervenções realizadas por organizações da sociedade civil junto a escolas públicas situadas nessas localidades. Ao situar a educação como a principal ferramenta de interrupção do ciclo de transmissão transgeracional da pobreza, o impacto desse cenário de segregação social sobre as escolas situadas nas regiões mais vulneráveis é trazido para o centro do debate. Nesse contexto, discute-se a experiência da Fundação Tide Setubal no bairro de São Miguel Paulista, na perspectiva de acrescentar alguns elementos ao diálogo, cada vez mais necessário, entre as políticas públicas e o terceiro setor, tendo em vista o enfrentamento dos problemas da educação pública nos espaços urbanos segregados.

setor há mais de 20 anos.

Atualmente coordena

PALAVRAS-CHAVE

o Núcleo de Gestão

do Conhecimento da Fundação Tide Setubal.

Educação integral. Vulnerabilidade social. Terceiro setor. Periferias urbanas. Território. 
INTRODUÇÃO

O presente artigo tem por objetivo discutir como as intervenções realizadas por organizações da sociedade civil junto a escolas públicas podem contribuir para o fortalecimento da educação formal nos territórios urbanos de alta vulnerabilidade social.

A questão parte de uma leitura dos problemas sociais que atingem espaços urbanos segregados e dos processos que têm engendrado o progressivo agravamento desse quadro, com sérias consequências para a qualidade da educação pública nas grandes cidades. Como veremos a seguir, é nesse contexto que as propostas relacionadas à perspectiva da educação integral ganham consistência e revelam-se, por um lado, potentes e factíveis, muito embora, por outro, portem desafios que convém destacar.

Compreender a complexidade desse cenário é, portanto, ponto de partida para uma reflexão voltada a desvelar formas de contribuir com o desenvolvimento da educação pública nas metrópoles. Com base nesse debate teórico, será discutida a experiência da Fundação Tide Setubal (FTAS) que, há cinco anos, trabalha pelo desenvolvimento local do bairro de São Miguel Paulista, situada na zona leste da cidade de São Paulo. Por não se atrelar especificamente ao campo da educação, a atuação da Fundação com as escolas porta especificidades que, como abordaremos adiante, a tornam fecunda para a presente discussão. ${ }^{1}$

VULNERABILIDADE SOCIAL E A SEGREGAÇÃO DOS POBRES URBANOS

A noção de vulnerabilidade social tem sido amplamente utilizada no campo das ciências sociais para fomentar o desenho de políticas públicas e outras ações voltadas aos grupos de maior fragilidade socioeconômica. Inúmeros autores trabalharam essa noção como pertinente ao padrão de desenvolvimento urbano na América Latina, onde as camadas populares e médias estão fortemente expostas aos problemas sociais decorrentes da pobreza e da insuficiência de políticas estatais que assegurem o bem-estar público (KATZMAN, 2001; BUSSO, 2001; PIZARRO, 2001; FILGUEIRA, 2001, entre outros).

Em síntese, as ideias apresentadas por esses autores convergem para

Informações sobre as experiências discutidas neste artigo foram obtidas em reuniões com a equipe da Fundação Tide Setubal e por meio de entrevistas individuais realizadas com os coordenadores de núcleos José Luiz Adeve (Cometa), Viviane Hercowitz e Mauro Bonfim. 
a definição da situação de vulnerabilidade social como um processo multidimensional que abarca uma análise dos riscos a que estão expostos indivíduos, famílias e comunidades, da estrutura de oportunidades que Ihes estão disponíveis e dos recursos que possuem para aproveitá-las e defender-se desses riscos. Essa análise é realizada, portanto, a partir de uma combinação entre fatores internos e externos, como se verá a seguir.

Esses fatores externos caracterizam-se pelas ofertas do Estado, do mercado e da sociedade nas mais diversas áreas, como o trabalho, a educação, a saúde, a cultura, etc. Nos locais em que essas ofertas forem maiores e apresentarem serviços de melhor qualidade, certamente haverá uma situação de vulnerabilidade menor. Outro fator externo importante nessa análise é o grau de exposição a riscos naturais, como secas, inundações ou terremotos, e sociais, como a violência urbana, a possibilidade de perder uma determinada situação econômica, de não ser atendido diante de uma emergência em saúde, etc. Evidentemente, quanto maior a exposição a esses riscos, maior a vulnerabilidade social.

Os fatores internos, por sua vez, referem-se aos recursos físicos, financeiros e simbólicos de que cada indivíduo, família ou comunidade dispõe para conduzir sua vida. Esses recursos abrangem itens como renda, reservas financeiras, bens e meios de trabalho; características familiares, como ciclo de vida, escolaridade e composição familiar; e, ainda, o que se costuma chamar "capital humano" ou "ativos pessoais", que designam atributos intangíveis que se refletem na capacidade de cada um para usar de forma eficiente seus recursos físicos e financeiros, para desfrutar de oportunidades e para construir estratégias que permitam minimizar o impacto das adversidades. Outro componente desses fatores internos, situado ao lado do capital humano, é o que se denomina "capital social”, que se refere aos recursos instalados nas relações, redes e laços de confiança e solidariedade. Nesse sentido, afirma-se que, quanto mais fortes os capitais humano e social, menor a situação de vulnerabilidade.

Embora vulnerabilidade social e pobreza sejam frequentemente tratadas como equivalentes, o rigor no uso dos termos apresenta diferenças importantes, pois a insegurança e o desamparo característicos das situações de vulnerabilidade não são necessariamente frutos da insuficiência de renda (PIZARRO, 2001, p.7). Em grande parte, podem-se associar essas vivências à instabilidade e à precariedade do emprego; à ineficiência dos sistemas de saúde e de educação para promoverem o fortalecimento do capital humano de indivíduos e famílias; e ao esgarçamento da rede de proteção oferecida pelo 
Estado (PIZARRO, 2001, p.12). À diferença da ideia de pobreza, apoiada em aspectos descritivos que deixam de lado as análises causais, a abordagem do fenômeno por meio da noção de vulnerabilidade permite aprofundar o estudo das relações entre a estrutura da sociedade, as instituições econômico-sociais e os impactos gerados em indivíduos, famílias e comunidades em diferentes esferas da vida (PIZARRO, 2001).

Apoiada nessa leitura, a avaliação das condições de vida nas cidades passará a incluir, necessariamente, um olhar acurado para o espaço urbano, considerando o georreferenciamento de suas ofertas e riscos. Por esta razão, em grandes metrópoles como São Paulo, é imprescindivel que tal avaliação leve em conta sua fragmentação territorial e encontre formas de distinguir as áreas urbanas que apresentam altos níveis de qualidade de vida daquelas que concentram as parcelas mais vulneráveis da população. Foi com essa preocupação, por exemplo, que a Fundação Seade criou o Índice Paulista de Vulnerabilidade Social (IPVS), capaz de identificar, em cada bairro da capital paulista, as áreas que demandam maiores investimentos por parte do Estado. ${ }^{2}$

Por motivos de síntese, não nos deteremos nos processos sociais que são responsáveis por essa fragmentação do espaço. No entanto, procuraremos colocar em evidência que o desinvestimento público que assola os territórios mais vulneráveis na cidade acarreta o crescente agravamento da situação.

Em sua análise sobre a situação de vulnerabilidade social das cidades da América Latina, Katzman (2001) ressalta o progressivo aumento da disparidade social entre pobres e não pobres. Entre as muitas explicações para compreender o processo, o autor destaca o fato de que as famílias que têm renda mais alta passam a buscar serviços que possuem qualidade superior àqueles oferecidos à população geral (KATZMAN, 2001, p.173). No plano da moradia, do trabalho, da saúde e da educação, esse fenômeno é facilmente observável: os ricos vão a escolas de ricos, moram em bairros nobres e utilizam serviços de saúde de alto nível; os pobres, em outro extremo, estão homogeneamente confinados em territórios precários, com serviços e equipamentos de baixa qualidade em todas as esferas.

Entre as várias consequências engendradas nesse cenário, três processos

2 O IPVS incide sobre cada setor censitário do município de São Paulo e classifica cada uma dessas áreas de acordo com critérios socioeconômicos e demográficos, cujos dados são extraídos do Censo. 0 indicador resultante é um número de 1 a 6 , que indica o nível de vulnerabilidade de cada unidade territorial. Informações detalhadas sobre o uso desse indicador estão disponíveis em: www.seade.gov.br/projetos/ipvs. 
podem ser destacados como ingredientes capazes de potencializar 0 agravamento da situação: a redução da sociabilidade informal entre diferentes estratos socioeconômicos que usam os mesmos serviços; 0 encolhimento dos problemas comuns que as famílias de diferentes níveis socioeconômicos enfrentam no dia a dia e a perda do apoio que os serviços públicos encontram no atendimento às camadas sociais que têm maior voz política para garantir a qualidade dos recursos públicos (KATZMAN, 2001, p.184). Nota-se, pois, a formação de um ciclo vicioso, alimentado pela crescente diferença de qualidade entre serviços públicos e privados, que tende a acentuar a disparidade dos pobres em relação ao resto da sociedade (KATZMAN, 2001, p.173).

Em última instância, pode-se dizer que a fragmentação dos espaços sociais forma "guetos" de pobreza, onde circulam menor quantidade, qualidade e diversidade de recursos (BUSSO, 2001, p.7). Nesses guetos, deterioram-se progressivamente os serviços públicos que poderiam fortalecer o capital humano de indivíduos e famílias, como a educação, o trabalho, e a saúde, e fragiliza-se a possibilidade de contar com redes de solidariedade capazes de favorecer o acesso a melhores condições de vida, já que a grande maioria das pessoas com as quais se convive é igualmente pobre e vulnerável.

A concentração espacial dessa população reforça, pois, a precariedade do grupo (KATZMAN, 2001, p.181). As interações sociais na vizinhança revelamse ineficazes para a obtenção de empregos; restritas ao convívio com pessoas que não alcançaram êxitos sociais com suas habilidades e hábitos; marcadas pela instabilidade no trabalho e pela consequente dificuldade de se organizar coletivamente para o exercício de algum controle social informal; frágeis quanto à oferta de modelos bem-sucedidos, de acordo com os valores sociais vigentes, para crianças e jovens; mais suscetiveis de procurar fontes ilegais de renda (KATZMAN, 2001). Esse último ponto ganha importância em contexto de privação material prolongada, pois, ainda que a comunidade rejeite esses hábitos, as dificuldades de sobrevivência aumentam a tolerância a essas práticas, o que, a longo prazo, faz crescer a distância entre os códigos dominantes nessas localidades e aqueles que predominam no restante da cidade, contribuindo para a segregação social (KATZMAN, 2001).

Os pobres urbanos sofrem, portanto, de um isolamento social crescente, o que os impede de acumular os ativos que seriam necessários para sair da pobreza (KATZMAN, 2001, p.173). À medida que o esgarçamento da rede de proteção social do Estado impõe às famílias a necessidade de manejar seus próprios 
recursos (PIZARRO, 2001, p.12) para alcançar patamares de vida superiores às condições encontradas no nascimento, o que se observa é a acentuação de uma tendência que aponta exatamente para o sentido oposto, isto é, para o progressivo empobrecimento desses recursos. Como resultado, as famílias pobres encontram-se em uma situação social estanque, cujas condições de superação tornam-se cada vez mais distantes. Nesse contexto, instala-se um poderoso ciclo de transmissão transgeracional da vulnerabilidade social.

IMPACTOS DA VULNERABILIDADE E DA SEGREGAÇÃO SOCIAL NA EDUCAÇÃO

Ao considerarmos a educação como a principal ferramenta de interrupção do ciclo de transmissão transgeracional da pobreza, posto que se trata da principal forma de fortalecimento do capital humano de indivíduos, famílias e comunidades, cabe investigar o impacto desse cenário de segregação social sobre as escolas situadas nas regiões mais vulneráveis, a fim de identificar formas de contribuir para a reversão desse quadro.

Estudo recentemente realizado pela Fundação Tide Setubal, em parceria com o Cenpec, a Fundação Itaú Social e o Unicef, destacou que a segregação socioespacial e a concentração de pobres em áreas isoladas representam fatores preponderantes na determinação desse quadro (ÉRNICA; BATISTA, 2011). Por meio da comparação entre escolas do bairro de São Miguel Paulista, na cidade de São Paulo, situadas em áreas de vulnerabilidade alta, média e baixa, segundo o IPVS, a pesquisa apontou conclusões importantes para a apreensão dos mecanismos que limitam o desenvolvimento de uma educação de qualidade nas grandes cidades. Conclusões que, como veremos adiante, merecem atenção no desenvolvimento de intervenções que procurem contribuir para o aprimoramento da educação pública.

Entre os processos que se refletem nos limites educacionais encontrados em territórios de maior vulnerabilidade, o estudo destacou que o isolamento da escola, resultado da escassa cobertura de equipamentos e serviços públicos e privados nessas áreas, implica a sobrecarga do espaço educativo com problemas sociais que não podem ser satisfatoriamente atendidos no âmbito da educação.

Nesse contexto, evidenciou-se, também, que a baixa oferta de educação infantil, em especial, contribui significativamente para o agravamento do quadro, pois, por ingressarem na escola somente no ensino fundamental, as crianças encontram-se privadas de condições importantes para o sucesso escolar.

Outros dois grandes fatores que também influenciam a baixa qualidade do 
ensino, segundo a pesquisa, são a homogeneidade do corpo discente no que diz respeito aos baixos recursos socioculturais de suas famílias de origem e à residência em áreas vulneráveis como o entorno da escola, e a desvantagem das escolas situadas nessas áreas para arregimentar profissionais mais bem qualificados e alunos com recursos culturais mais elevados.

$\mathrm{Na}$ esteira desses dois últimos elementos, o estudo constata, enfim, a impossibilidade de a escola atuar de acordo com o modelo institucional que a orienta, pois, ao manter somente profissionais e alunos com baixos recursos socioculturais, a instituição encontra-se privada das condições que poderiam assegurar seu funcionamento adequado, de acordo com esse modelo.

Os aspectos que poderiam reverter esse cenário envolvem, pois, o investimento em um processo que alavanque, ao mesmo tempo, o desenvolvimento social do território e o desenho de políticas públicas especificamente voltadas para as escolas que atuam nessas localidades. Nesse sentido, não há dúvidas de que somente o Estado pode e deve se encarregar de uma tarefa de tal complexidade e abrangência. No entanto, é no chamado terceiro setor que têm residido muitas das iniciativas implicadas com essa transformação, de modo que, para fomentar o desenho de novas políticas nesses territórios, torna-se necessário olhar para essas experiências e para o conhecimento que produzem e acumulam.

\section{A EDUCAÇÃO INTEGRAL EM TERRITÓRIOS VULNERÁVEIS}

É nesses territórios de alta vulnerabilidade social que a atuação das organizações não governamentais se faz especialmente notar. Segundo o IBGE, ${ }^{3}$ em 2005 havia quase 47 mil fundações privadas e associações sem fins lucrativos no Brasil ligadas à cultura e recreação e 2.388 classificadas como “outras formas de educação e ensino”. No Estado de São Paulo, 42.676 entidades estavam cadastradas e ativas no Sistema Pró-Social até agosto de 2011. Os números certamente são mais elevados se considerarmos o grande número de instituições que não estão regularizadas ou cadastradas, mas desenvolvem ações nas áreas de educação e cultura.

Em grande parte delas, um histórico de mobilização pela defesa de direitos acaba por gerar, em dado momento, a necessidade de institucionalização. Via de regra, as pequenas associações nascem da atuação de lideranças locais ou

3 Disponível em: «http://www.ibge.gov.br/home/estatistica/economia/fasfil/2005/notastecnicas.pdf.

4 Disponivel em: «http://www.desenvolvimentosocial.sp.gov.br/portal.php/entidades-sociais_entidades`.

"Relação de Entidades e Organizações de Assistência Social do Estado de São Paulo, Cadastradas e Ativas no Sistema Pró-Social/Instituições até 15/08/2011". 
de grupos de determinada região que iniciam suas ações sociais de maneira informal, pouco organizada e com recursos ínfimos. Aos poucos, esses grupos evoluem, legalizam-se e passam a ter uma atuação mais consistente e em geral muito próxima das demandas da população do entorno. Isso pode ser bastante positivo no sentido da escuta àqueles a quem atendem e da identificação com eles, mas igualmente negativo, na medida em que pode reproduzir uma visão de gestão institucional baseada no clientelismo e no assistencialismo. ONGs têm, portanto, exercido um papel fundamental na educação de crianças, jovens e adultos de setores mais pobres da população, embora, frequentemente, realizem ações pulverizadas, pouco articuladas com o poder público ou mesmo com outras entidades educativas.

As diversas ações voltadas à educação integral surgidas nos últimos anos 5 têm se articulado a propostas consistentes de melhoria desse quadro. Embora o conceito de educação integral ainda esteja em movimento, é consenso entre os atores envolvidos a necessidade de ampliar as ações educativas no que tange ao tempo, aos espaços, métodos, estratégias e conteúdos de aprendizagem na perspectiva de construção de uma sociedade democrática. Em decorrência dos mais variados fatores - defesa dos direitos, uma concepção de desenvolvimento infantil mais holística, uma reorganização do currículo escolar, defesa da escola pública, um projeto totalizador da política social, o fortalecimento de uma comunidade de aprendizagem ou a consolidação de uma rede educativa (AFONSO, 2001; BATISTA; FREIRE de ANDRADE, 2010; TORRES, 2003; GUARÁ, 2003; CENPEC, 2006; FUNDAÇÃO ITAÚ SOCIAL/ CENPEC, 2011), vários são os argumentos favoráveis à construção de uma educação integral que vai muito além da ampliação da jornada escolar.

A formação de crianças e adolescentes não se limita mais à educação familiar ou escolar (educação formal), ela se espraia por outros domínios, campos de conhecimento e instituições que abrigam, acolhem e trabalham com esse público das mais diversas formas. A educação integral é uma perspectiva que visa fortalecer alianças entre segmentos do poder público, entre este e o terceiro setor, entre a educação formal e informal, em uma concepção de educação intersetorial, multidisciplinar, que responsabiliza toda a sociedade e, portanto, com mais chances de sucesso ao integrar famílias-escolascomunidades. Como afirmam Batista e Freire de Andrade (2010, p.6),

A proposta de educação integral na interface educação-proteção social baseia-se na intersetorialidade, exigindo articulações com outros setores públicos e da sociedade para a promoção de ações de desenvolvimento social, de cultura, de esporte e lazer, de saúde, ampliando suas funções e responsabilidades.

Dentre as publicações mais recentes, ressaltamos as experiências descritas na pesquisa publicada em Tendências para Educação Integral (FUNDAÇÃO ITAÚ SOCIAL/CENPEC, 2011). 
Essa perspectiva não floresce em virtude do mau desempenho da educação escolar e, nesse sentido, não é uma crítica à escola. Ela defende uma proposta de educação mais abrangente e supostamente mais eficaz porque integraria saberes e práticas, contextos culturais variados e, sobretudo, uma visão holística, uma vez que considera os diversos aspectos do desenvolvimento humano - afetivo, físico, intelectual ou mesmo espiritual. Ainda que algumas ideias defendidas nesse campo guardem uma concepção romântica e edulcorada de homem, é fato que,

Na perspectiva dos direitos, para que a criança e o adolescente - sujeitos em condição peculiar de desenvolvimento - atinjam o padrão de cidadania, o Estado deve garantir que todas as áreas da política pública, especialmente aquelas que possam promover o desenvolvimento pessoal, social e humano, ofereçam-lhes proteção. (GUARÁ, 2003, p.36)

A sociedade contemporânea demanda que o Estado abrigue crianças e jovens de forma segura e responsável com vistas ao seu pleno desenvolvimento, mas também como meio de desonerar os pais e familiares das demandas relativas aos cuidados com os mais novos. Como resultado, encontram-se adultos mais disponíveis para o trabalho, o cuidado com a saúde, o acompanhamento da escolarização dos filhos e outras atividades que possam nutrir o núcleo familiar e favorecer o uso eficiente de seus recursos físicos, financeiros e simbólicos. Desde os anos 1990, a legislação brasileira tem caminhado no sentido de fortalecer a rede de proteção à infância e adolescência por meio de mecanismos que facilitam ou garantem a educação integral. ${ }^{6}$ Com essa perspectiva, programas governamentais têm sido implementados, como, recentemente, o "Mais Educação",7 que oferece recursos materiais para suprir as necessidades das escolas, com o objetivo de melhorar a educação das crianças.

Segundo documento Manual da Educação Integral do MEC, "A Educação Integral está presente na legislação educacional brasileira e pode ser apreendida em nossa Constituição Federal, nos artigos 205, 206 e 227; no Estatuto da Criança e do Adolescente (Lei no 9089/1990); na Lei de Diretrizes e Bases (Lei no 9394/1996), nos artigos 34 e 87; no Plano Nacional de Educação (Lei no 10.179/01) e no Fundo Nacional de Manutenção e Desenvolvimento do Ensino Básico e de Valorização do Magistério (Lei no 11.494/2007). Por sua vez, a Lei no 10.172, de 9 de janeiro de 2001, que instituiu o Plano Nacional de Educação (PNE), retoma e valoriza a Educação Integral como possibilidade de formação integral da pessoa. O PNE avança para além do texto da LDB, ao apresentar a educação em tempo integral como objetivo do Ensino Fundamental e, também, da Educação Infantil (retirado de manual 2011-programamaiseducao-110621074418-phpapp02).

7 Criado pela Portaria Interministerial no 17/2007, o Programa tem o objetivo de aumentar a oferta educativa nas escolas públicas por meio de atividades optativas agrupadas em macrocampos como acompanhamento pedagógico, meio ambiente, esporte e lazer, direitos humanos, cultura e artes, cultura digital, prevenção e promoção da saúde, educomunicação, educação científica e educação econômica. A iniciativa do Programa partiu da Secretaria de Educação Continuada, Alfabetização e Diversidade (Secad/MEC), em parceria com a Secretaria de Educação Básica (SEB/MEC) e com as secretarias estaduais e municipais de Educação. Sua operacionalização é feita por meio do Programa Dinheiro Direto na Escola (PDDE), do Fundo Nacional de Desenvolvimento da Educação (FNDE).

cadernoscenpec| São Paulo|v.1| n.1| p. 35-57 | dez. 2011 
Desse modo, políticas públicas na área da educação vêm investindo na criação de uma escola não somente de jornada ampliada, mas também mais articulada a seu entorno. A escola pública vem sendo desafiada a fazer escolhas no sentido da superação de suas principais dificuldades, em especial, a melhoria da qualidade da aprendizagem dos alunos. Para isso, precisará integrar saberes, interesses, competências, habilidades em um mundo cada vez mais heterogêneo e volátil, enfrentando as dificuldades implicadas na formação pessoal e profissional de crianças e jovens. Novos paradigmas do conhecimento, do ensino e da aprendizagem precisam ser construídos e, certamente, não caberá apenas à escola essa tarefa.

A cultura, o esporte, a assistência social, o meio ambiente, a saúde são áreas que se complementam, podendo gerar economia de recursos e resultados muito satisfatórios se ações, originadas de políticas públicas ou não, fossem integradas. No mais das vezes, grupos informais ou organizações não governamentais dos mais diversos tipos têm se incumbido dessas ações educativas, sejam elas recreativas ou mesmo ligadas à profissionalização de jovens.

Apesar dos avanços, em grande parte dos casos, educação formal e informal realizam um trabalho que caminha em linhas paralelas, sem que haja pontos de intersecção; o trabalho articulado entre ONGs e escolas ainda é processo difícil de se efetivar. Por um lado,

As ONGs têm dificuldade em compreender as lógicas de funcionamento, a estrutura pedagógica, as relações internas entre os atores sociais, a cultura institucional e um conjunto de outras questões que permeiam o cotidiano das escolas, decorrentes da vinculação ao sistema oficial de ensino.

(INSTITUTO CREDICARD, 2007, p. 21)

Por outro, muitas escolas mantêm uma postura de concorrência e desconfiança do trabalho realizado pelas ONGs por entender que a ludicidade e o aspecto recreativo de suas propostas não são verdadeiramente eficazes na educação de crianças e jovens (MONTEIRO da SILVA, 2010). O diálogo e a articulação são cada vez mais necessários, uma vez que o papel das ONGs como parceiros será ainda mais expressivo: "se a dinâmica e a estrutura funcional são diversas, o objetivo educativo é similar, o que por si só poderia facilitar os contatos e sedimentar alianças” (GUARÁ, 2003, p.41).

A experiência na Fundação Tide Setubal com as escolas de São Miguel Paulista evidencia que a ação conjunta se constrói a partir do reconhecimento das diferenças radicais entre os atores envolvidos e do caráter "inacabado", "insuficiente", "incompleto" das ações em parceria. Partimos do pressuposto de que é em rede que ocorre maior sinergia entre ações diversificadas, é no 
coletivo que os problemas são diagnosticados e as soluções elaboradas, o que resulta em trabalho otimizado dos diferentes parceiros.

Colocar essas experiências em discussão tem como perspectiva acrescentar alguns elementos ao tema espinhoso da educação pública nos espaços urbanos segregados. Evidentemente, inúmeras são as organizações que, por desenvolverem trabalhos especializados no campo da educação, têm se implicado com o tema e produzido saberes de grande relevância para a atuação nesses contextos. É pela valorização dessas práticas e pelo reconhecimento do árduo terreno ao qual se dedicam que procuramos, neste artigo, trazer a contribuição da Fundação Tide Setubal.

O compromisso da Fundação com o desenvolvimento local do território, em face do cenário de vulnerabilidade social encontrado em periferias urbanas, com é o caso de São Miguel Paulista, convoca a reflexão sobre os avanços educacionais que podem ser obtidos por escolas públicas situadas nessas localidades. Embora os espaços de educação informal e o trabalho das ONGs tenham inquestionável valor nesses territórios, a presente discussão focalizará, precisamente, articulações que possam refletir na melhoria da educação formal. Como veremos a seguir, ao adentrarem o espaço escolar, as ações do terceiro setor, por sua intensa conexão com o território, podem contribuir para que sejam movimentados elementos importantes para o desenvolvimento de uma escola em sintonia mais fina com a realidade local.

A experiência da Fundação Tide Setubal junto Às escolas de São Miguel PAULISTA

A atuação da Fundação Tide Setubal junto às escolas tem raízes em sua ligação com sua missão institucional, cujo foco está no desenvolvimento local do território onde realiza suas atividades, e não com as questões específicas da educação formal. Nesse sentido, a experiência porta particularidades que merecem ser discutidas com o intuito de contribuir com o debate acima apresentado.

O conhecimento acumulado em mais de cinco anos de ação direta com crianças, jovens e famílias tem conferido legitimidade ao trabalho realizado pela Fundação no território e fomentado o desenvolvimento de ações de formação estreitamente conectadas à realidade local. Essas ações fundamentam-se na expertise em desenvolver propostas que favoreçam o envolvimento da população com questões coletivas, a participação no território e a melhoria das relações na comunidade. 
Nesse contexto, ao foco no fomento ao capital humano e social no território soma-se o trabalho de fortalecimento institucional realizado junto a ONGs, escolas, grupos de trabalho, unidades de saúde, coletivos, fóruns e associações, sempre com o intuito de impulsionar a articulação de um tecido social capaz de fazer frente às adversidades do cotidiano, de reivindicar direitos e de buscar alternativas para melhorar a qualidade de vida no bairro.

A princípio, a aproximação da Fundação com as escolas limitou-se ao estabelecimento de um diagnóstico local que mostrava que as questões educacionais do território estavam alinhadas ao panorama geral do País (CORTESE, 2006, p.1). Conquistas que haviam atingido o Brasil como um todo, como avanço na oferta de vagas, queda da taxa de repetência e da defasagem idade/série e acesso ao ensino médio, contrastavam com o fato de permanecerem inatingidas as metas relativas ao atendimento da criança até seis anos, à conclusão do ensino fundamental e médio e à política de formação inicial e continuada dos professores.

Atenta à importância da educação integral, entendida como a oferta de oportunidades de aprendizagem dentro e fora do espaço escolar, a Fundação procurava, desde então, identificar possibilidades de articulação entre escolas e ONGs de São Miguel Paulista. A constatação da falta de atividades de lazer, esporte e cultura na região abriu espaço para a atuação da Fundação nessa esfera, assim como no fortalecimento dos Núcleos de Ação Educativa (CORTESE, 2006, p.3), atualmente chamados de Centros para a criança e para 0 adolescente (CCAs).

Apesar das dificuldades encontradas no início da atuação com as escolas, ${ }^{8}$ a Fundação Tide Setubal fez esforços progressivos nessa aproximação, tendo em vista a abertura das instituições para o território e a integração das práticas escolares às outras oportunidades de aprendizagem que os projetos da Fundação engendravam.

Os conflitos identificados na relação entre família e escola e entre jovens e educadores tornaram-se recorrentes em diversas atividades de nossos projetos. Nesse sentido, a importância das relações humanas na escola é

8 Uma primeira análise da relação da FTAS com as escolas já apontava algumas dificuldades. Observou-se que os profissionais das escolas mostravam-se ameaçados, desconfortados e possivelmente receosos diante de uma pretensa interferência nas atividades pedagógicas, além de se manterem excessivamente ocupados com o cumprimento de obrigações com as instâncias superiores e com a solução de problemas do cotidiano escolar (CORTESE, 2006, p.3). Uma situação mais favorável para a parceria se estabelecia em escolas que contavam com ao menos um educador comprometido com a comunidade (CORTESE, 2006). 
evidenciada e se reconhece a urgência com que essas questões devem ser tratadas, apoiando-se em valores como respeito, tolerância e valorização da diversidade, bem como na importância do desenvolvimento de competências para a solução não violenta de conflitos (SETUBAL, 2008).

Outra questão que ganha destaque a partir dessa experiência diz respeito ao profundo sentimento de impotência, aliado a uma postura de imobilidade, que parece contagiar todos os que trabalham no ambiente escolar. A complexidade inerente à situação de vulnerabilidade do território traz para a escola dificuldades que têm impacto de diferentes formas nos educadores (sentem-se impotentes, culpabilizam as famílias, responsabilizam instâncias superiores, etc.). Nesse sentido, a Fundação passa a assumir em sua relação com as escolas o desafio de atuar sem cair na "armadilha imobilizadora colocada sempre pelos professores" (SETUBAL, 2008, p.4). Por isso, assume o compromisso de valorizar a potência da equipe escolar, apresentar alternativas de ação e trabalhar para que os professores se envolvam cada vez mais com a responsabilidade pela aprendizagem.

FOCO DA ATUAÇÃO DOS NÚCLEOS DE AÇÃO NO TERRITÓRIO COM AS ESCOLAS

A experiência nesse território ${ }^{9}$ tem demonstrado que certas práticas favorecem a entrada de uma ONG ou de um projeto na escola e facilitam seu desenvolvimento, enquanto outras produzem efeitos negativos para o trabalho. É possível identificar quatro aspectos da relação da Fundação com as escolas que merecem destaque e serão objeto de aprofundamento a seguir:

1. Valorização da potência da equipe escolar

2. Incentivo às práticas que consolidem a educação integral no território

3. Investimento na importância das relações humanas na escola

4. Ênfase na aprendizagem, sobretudo, no letramento

\section{VALORIZAÇÃO DA POTÊNCIA DA EQUIPE ESCOLAR}

A entrada das ações nas escolas exige muito diálogo com a direção e coordenação pedagógica. Levar um projeto previamente elaborado, sem

As experiências foram realizadas pelos núcleos de Comunicação Comunitária, Mundo Jovem e CPDOC da Fundação Tide Setubal. Algumas delas podem ser acessadas no site da instituição: www.ftas.org.br. 
abertura para ouvir as demandas da realidade escolar ou oferecer um projeto como "a grande solução" para os problemas da escola parecem ser maneiras de provocar rapidamente sua rejeição. Em geral, tem sido importante conhecer os projetos já desenvolvidos na instituição antes de propor uma nova ação, assim como se mostra relevante reconhecer a quantidade de intervenções já realizadas na escola, e também as diversas tentativas de solucionar os problemas existentes. Desse modo, valoriza-se a equipe escolar e procurase fazer com que a intervenção da Fundação Tide Setubal ocupe um lugar estratégico ao potencializar as demais iniciativas.

Esse objetivo explicita-se de forma clara ao se desenhar a intervenção de determinado programa/núcleo a partir das demandas escolares e de construir com a escola as atividades a serem desenvolvidas, o que implica variações no modo como o projeto acontece em cada instituição. Assim como as intervenções realizadas no território incorporam ao seu desenho a escuta à comunidade, a ação com as escolas sustenta-se nessa forma de articulação, ainda que diferentes concepções e modos de agir possam se explicitar no decorrer do percurso. Entende-se, pois, que esta é uma importante contribuição da Fundação às escolas situadas em territórios vulneráveis: colocar em prática a possibilidade de agir conjuntamente, de agregar saberes e legitimar as diferenças como ferramentas de ação.

Uma forma encontrada para integrar os projetos da Fundação às demais atividades da instituição e fortalecê-las foi inserir as atividades em contextos já existentes e legitimados pelos professores, como o Projeto Estratégico de Ação (PEA) e a Jornada Especial Integral de Formação (JEIF) das escolas municipais, e as Jornadas Extraordinárias (JEX) das escolas estaduais. Ao proceder dessa forma, as atividades são reconhecidas em sua importância para a instituição, podem ser previstas no cronograma escolar e contar com o trabalho remunerado dos professores que se envolvem com a proposta.

A formalização das atividades nesses espaços tem sido desejável em todos os casos, embora nem sempre possível. Procura-se, com isso, evitar a sobrecarga do professor e, fundamentalmente, assegurar a manutenção de seu foco na aprendizagem. É preciso evidenciar que as propostas desenvolvidas nas articulações da Fundação com as escolas têm como objetivo contribuir para a qualidade da educação escolar, e não expandir a atuação da escola para outras áreas. A integração das atividades ao projeto político-pedagógico da instituição é, nesse sentido, condição para um trabalho fértil.

O constante diálogo com a coordenação pedagógica da escola constitui 
elemento decisivo para a sustentação do projeto e o envolvimento da instituição como um todo. Muitas vezes, nem todos os projetos desenvolvidos em parceria com escolas são abraçados por todos os professores; por essa razão, é importante que exista na própria escola uma sustentação que ampare esses professores para os desafios do trabalho, o que, em geral é papel dos coordenadores. Portanto, o fortalecimento dos coordenadores mostra-se fundamental porque são eles que oferecem suporte cotidiano aos professores e podem construir ou fortalecer ações de troca entre as escolas.

A importância de respeitar o tempo e a rotina da escola também se apresenta como um elemento fundamental na prática de diálogo e construção conjunta. Diversos feriados, festas comemorativas e urgência no atendimento a compromissos com instâncias superiores implicam alterações no ritmo do projeto e mudanças significativas no cronograma. A disponibilidade para acolher essas questões e adaptar-se ao cronograma escolar torna-se condição para que a intervenção aconteça.

2. INCENTIVO ÀS PRÁTICAS QUE CONSOLIDEM A EDUCAÇÃO INTEGRAL: ABERTURA PARA O TERRITÓRIO

Consoante aos princípios da educação integral, as ações implementadas pela Fundação Tide Setubal procuram investir na possibilidade de educadores e educandos aprofundarem seu olhar para o território - conhecerem o entorno, suas questões e seus recursos. Isso ocorre, por exemplo, em ações do CPDOC cujo foco central é a implicação da escola na preservação da memória do bairro. Também no Núcleo de Comunicação Comunitária, ao produzirem peças de comunicação (jornal, TV de rua, rádio de rua), os jovens se apropriam dos problemas, recursos e serviços da comunidade, ampliando sua percepção sobre o local onde vivem e seu papel social. Em outra vertente desse mesmo projeto, professores e alunos se integram na construção de uma rede de trocas entre escolas no território, o que permite, de outra maneira, estar na comunidade onde se vive, nela transitar e divulgá-la.

A escola e a ONG fazem parte da mesma comunidade de aprendizagem. Uma criança é aluno da escola, mas é também educando de um projeto social, membro da igreja ou atleta do time de futebol do bairro. 0 mesmo acontece com os professores que, com muito mais frequência do que ocorria anos atrás, habitam perto das comunidades onde trabalham. Conhecer os diferentes papéis sociais que cada um exerce e levá-los em conta nas práticas escolares implica um reconhecimento do território e dos sujeitos em suas diversas dimensões. 
Há ainda que considerar a importância das ONGs no que se refere à variedade de práticas, à maior flexibilidade no atendimento das demandas da comunidade: "as organizações da sociedade civil muito raramente podem universalizar experiências, mas elas podem ser excelentes laboratórios de políticas públicas a serem encampadas pelo Estado" (ÉRNICA, 2006, p.28).

\section{INVESTIMENTO NAS RELAÇÕES HUMANAS}

A experiência com os jovens, mães e pais participantes dos nossos projetos explicita a importância da escola para essa população e o desejo, unânime, de contar com um ambiente escolar acolhedor e propício ao desenvolvimento de todos. Fortemente ancorada nas ideias da educação para a convivência, a Fundação, de diferentes maneiras, procura intervir na possibilidade de redimensionar a relação entre professores e jovens, de modo a ampliar oportunidades de troca, diálogo e construção conjunta.

Grande parte das ações desenvolvidas na Fundação parte do princípio que alunos e professores possuem saberes específicos que, muitas vezes, se complementam. Assim, procura-se convidaros educadores a mudar de posição ao se engajarem em atividades de maior escuta aos jovens e reconhecimento do seu saber. Isso ocorre, por exemplo, quando os professores são convidados a coordenar grupos de adolescentes e a mediar a troca de saberes entre eles; ou quando aprendem aspectos técnicos das ferramentas tecnológicas com os jovens e os ensinam a analisar criticamente as informações a que têm acesso pelos meios digitais. Em muitos casos, lançar-se a essa troca frutífera ainda é muito desafiador para alguns professores, pois exige que se disponham a entrar em uma relação mais horizontal com os alunos e a aprender com eles, sem que, por isso, deixem de ensinar e de se posicionar como educadores. Isso nem sempre é fácil. Muitas vezes, essas situações despertam dúvidas e inseguranças nos professores quanto a como se posicionar, o que responder e como trabalhar com o que os alunos trazem. O desafio consiste em criar condições para que os professores se sintam suficientemente seguros para acolher as questões, conflitos e opiniões dos alunos, bem como para se posicionar diante delas.

Ao investir nos recursos do professor para que ele possa ampliar a capacidade de continência para as questões da adolescência ou para experimentar papéis diferentes em sala de aula, abre-se a possibilidade de construir no grupo um ambiente favorável às trocas entre pares, com reflexos na melhoria das relações dos jovens entre si. 
Nesse sentido, o envolvimento da escola como um todo se mostra, novamente, fundamental para dar sustentação aos professores que participam das ações desenvolvidas pelos núcleos. É preciso que encontrem na instituição espaço de diálogo sobre as dificuldades enfrentadas.

\section{4. ÊNFASE NA APRENDIZAGEM, SOBRETUDO, NO LETRAMENTO}

Podemos afirmar que a aprendizagem e, sobretudo, o letramento está no foco estreito do trabalho da Fundação com as escolas, que procura, de diversas maneiras, criar formas lúdicas e consistentes de envolver jovens e educadores em diferentes atividades de leitura e escrita. Não por acaso, as professoras de Língua Portuguesa têm trabalhado as propostas de produção coletiva de peças de comunicação que atraem o interesse dos alunos.

Cabe destacar que as intervenções da Fundação nessa esfera implicam potencializar as boas práticas de ensino-aprendizagem existentes nas escolas e, ao mesmo tempo, abrir espaço para a reflexão e questionamento a respeito de práticas de má qualidade. Em nenhum momento se intervém no saber pedagógico dos educadores; o trabalho incide num plano mais abrangente, da intervenção institucional que visa colocar em circulação os saberes da equipe escolar, provocar o questionamento do que responde pelos problemas nessa esfera e estimular a busca por novos conhecimentos.

\section{CONSIDERAÇÕES FINAIS}

Como vimos, as intervenções realizadas por ONGs nos territórios vulneráveis revelam-se, de muitas maneiras, significativas para a população local. As atividades relacionadas à educação informal têm se destacado no cenário que inicialmente apresentamos, posto que contribuem significativamente para o fortalecimento do capital humano e social no território.

Sabe-se que a parceria ONG-escola pode se dar de muitas maneiras. No presente artigo, partimos de uma interrogação focada na possibilidade de as articulações entre ONG e escola nesses territórios contribuírem para o fortalecimento da educação formal, e não apenas (embora não menos importante) para a ampliação das ofertas de aprendizagem nos espaços comunitários. Aliada ao panorama da educação integral, a experiência da Fundação Tide Setubal junto às escolas de São Miguel Paulista foi discutida com o intuito de iluminar o debate. Dessa discussão, três elementos podem ser destacados. 
0 primeiro deles refere-se à importância do crescente investimento que se tem feito na criação de uma escola articulada a seu entorno. Isso pressupõe uma concepção de educação mais abrangente e demanda uma escola capaz de reconhecer o território como uma comunidade de aprendizagem que

Faz parte de e deve articular-se com um projeto de desenvolvimento local e nacional, integral e integrador [...] Assim, a comunidade de aprendizagem não é resultado da soma de intervenções isoladas, ou mesmo de sua articulação, e sim da construção de planos educativos territorializados.

(TORRES, 2003, p.87)

O fortalecimento da escola em sua articulação ao território é estratégico nesses cenários vulneráveis, pois envolve a estruturação de uma instituição chave na rede de ofertas sociais disponíveis. Chave porque, além de contribuir diretamente para o fomento do capital humano e social no território, a escola que se envolve nesse processo de integração à comunidade tende a se solidificar como instituição de referência para os moradores.

O segundo ponto a ser destacado refere-se precisamente a uma nuance importante para que a abertura da escola ao entorno reflita os ganhos educacionais esperados: é preciso zelar pela gradual articulação das questões emergentes do território a um trabalho educativo coeso. Em outras palavras, deve-se assegurar o foco na aprendizagem integrando as ações a um projeto pedagógico que contemple a realidade local.

O que tem se explicitado na atuação da Fundação é que essa integração da escola ao território se constrói gradualmente. A disponibilidade da instituição para se abrir à comunidade e conhecer a complexidade de seus problemas deve ser acompanhada por um trabalho formativo, que favoreça a leitura da realidade local e a construção de intervenções consistentes e pertinentes ao campo da educação. Em sentido contrário, a escola que procura contemplar os problemas locais sem integrar essas ações a seu projeto pedagógico recai em um empobrecimento, posto que o plano da aprendizagem perde espaço para demandas sempre urgentes, insistentes e alarmantes do território.

Nesse sentido, o terceiro e último elemento de destaque refere-se à valorização que a Fundação Tide Setubal tem feito de todas as ações de construção conjunta com a escola. É nesse exercício de confronto com a alteridade, de articulação a partir das diferenças entre os envolvidos que se têm revelado as maiores conquistas da parceria. A ação formativa ocorre, pois, nessas costuras cotidianas e horizontais, nas quais estão presentes o reconhecimento dos limites dessas relações, a necessidade de adequação mútua à rotina alheia, a impossibilidade de um encontro harmônico e plenamente satisfatório. 
0 método de intervenção, nesses casos, está estruturalmente fundado naquilo que se almeja como fim. Pois é somente a partir da certeza dessas limitações que a escola pode lançar-se ao território, sem perder seu claro posicionamento no campo da educação. 


\section{Contribution of the third sector to development of a school in line with local reality - the Fundação Tide Setubal experience}

ABSTRACT

With the aim of contributing to the strengthening of formal education in urban areas of high social vulnerability, this article discusses the intervention of civil society organizations within public schools located in these areas. When we consider education as the main tool for interrupting the transgenerational transmission cycle of poverty, the impact of this socially segregated scenario on schools located in the most vulnerable regions is brought to the center of the discussion. In this context, the Fundação Tide Setubal experience in São Miguel Paulista is discussed, with a view to adding some elements to the increasingly necessary dialogue between public policy and the third sector, aimed at tackling the problems of public education in segregated urban spaces.

\section{KEYWORDS}

Integral education. Social vulnerability. Third sector. Urban peripheries. Territory. 


\section{Referências}

AFONSO, A. J. Os lugares da educação. In: SIMSON, O. R. M.; PARK, M. B.; FERNANDES, R.S. (Org.). Educação não-formal: cenários da criação. Campinas: Unicamp, 2001. p. 29-38.

BATISTA, C. B.; FREIRE DE ANDRADE, V. Educação Integrada e espaços de aprendizagens: diálogos entre escola e projeto social. Gerais: Revista Interinstitucional de Psicologia, [S.I.], v.3, n.1, p. 2-11, 2010.

BRASIL. Ministério da Educação. Manual da Educação Integral em Jornada Ampliada para Obtenção de Apoio Financeiro por meio do Programa Dinheiro Direto na Escola - PDDE/ Educação Integral. Brasília, 2011.

BUSSO, Gustavo. Vulnerabilidad social: nociones e implicancias de políticas para América Latina y el Caribe a comienzos del siglo XXI. In: SEMINARIO INTERNACIONALSOBRE LAS DIFERENTES EXPRESIONES DE LA VULNERABILIDAD SOCIAL EN AMÉRICA LATINA Y EL CARIBE, 2001, Santiago del Chile. Anais do Seminário Internacional sobre Vulnerabilidade Social. Santiago de Chile: Cepal/Celade, 2001.

CENPEC. Seminário Nacional: tecendo redes para a educação integral. São Paulo: Cenpec, 2006. Disponível em: http://www.anj.org.br/jornaleeducacao/ biblioteca/publicacoes/TecendoRedesparaaEducacaolNtegral.pdf. Acessado em: 01/09/2011.

CORTESE, M. Educação integral, escolas e ONGs. São Paulo: Fundação Tide Setubal, 2006.

ÉRNICA, M. Percurso da Educação Integral no Brasil. In: SEMINÁRIO NACIONAL TECENDO REDES PARA A EDUCAÇÃO INTEGRAL, 2006, São Paulo. Anais do Seminário Nacional Tecendo Redes sobre Educação Integral. São Paulo: Cenpec, 2006.

ÉRNICA, M. e BATISTA, A. A. G.. Educação em territórios de alta vulnerabilidade social na metrópole: um caso na periferia de São Paulo. Cenpec: Informe de Pesquisa, [S.I.], n. 3, 2011.

FILGUEIRA, C.H. Estrutura de oportunidades e vulnerabilidad social: Aproximaciones conceptuales recientes. In: SEMINARIO INTERNACIONAL SOBRE LAS DIFERENTES EXPRESIONES DE LA VULNERABILIDAD SOCIAL EN AMÉRICA LATINA Y EL CARIBE, 2001, Santiago del Chile. Anais do Seminário 
Internacional sobre Vulnerabilidade Social. Santiago de Chile: Cepal/Celade, 2001.

FUNDAÇÃO ITAÚ SOCIAL; CENPEC. Tendências para Educação Integral. São Paulo: Fundação Itaú Social/Cenpec, 2011.

FUNDAÇÃO SEADE. Índice Paulista de Vulnerabilidade Social. Disponível em: http://www.seade.gov.br/projetos/ipvs/. Acessado em: 10/09/2011.

GUARÁ, I. M. F. da R. Educação, proteção social e muitos espaços para aprender. In: CENPEC. Muitos lugares para aprender. São Paulo: Cenpec/ Fundação Itaú Social/Unicef, 2003.

INSTITUTO BRASILEIRO DE GEOGRAFIA E ESTATÍSTICA. As Fundações Privadas e Associações sem Fins Lucrativos no Brasil - 2005. IBGE, 2005. Disponível em: http://www.ibge.gov.br/home/estatistica/economia/fasfil/2005/notastecnicas. pdf. Acessado em: 14/09/2011.

INSTITUTO CREDICARD (Org.); Esteves, S. (Coord.). Alianças e parcerias com escolas públicas. São Paulo: Via Impressa, 2007.

KATZMAN, R. Seducidos y abandonados: el aislamiento social de los pobres urbanos. Revista de la Cepal, Santiago de Chile, n. 75, dezembro de 2001.

MONTEIRO DA SILVA, D. ONGs e escolas públicas básicas: competição ou cooperação. In: III CONGRESSO INTERNACIONAL DE PEDAGOGIA SOCIAL, 3, 2010, São Paulo. Anais do Congresso Internacional de Pedagogia Social. São Paulo, 2010. Disponível em: 〈http://www.proceedings.scielo.br/scielo. php?script=sci_arttext\&pid=MSC0000000092010000100006\&lng=en\&nrm =abn>. Acesso em: 01 out. 2011.

PIZARRO, R. La vulnerabilidad social y sus desafios: uma mirada desde América Latina. Santiago de Chile: Cepal, 2001. (Série Estudios Estadísticos y prospectivos).

SECRETARIA DE DESENVOLVIMENTO SOCIALDO ESTADO DESÃO PAULO. Relação de entidades e organizações de assistência social do Estado de São Paulo. São Paulo, 2011. Disponível em: http://www.desenvolvimentosocial.sp.gov. br/a2sitebox/arquivos/documentos/284.pdf. Acessado em 14/09/2011.

SETUBAL, M.A. Fundação Tide Setubal e Relação com as escolas: alguns pontos para discussão [documento interno]. São Paulo: Fundação Tide Setubal, 2008. 
TORRES, R. M. A educação em função do desenvolvimento local e da aprendizagem. In: CENPEC. Muitos lugares para aprender. São Paulo: Cenpec/ Fundação Itaú Social/Unicef, 2003.

Recebido em: OUTUBRO DE 2011

Aprovado em: NOVEMBRO DE 2011 